\title{
Commentary \\ Dendritic cell defects in patients with cancer: mechanisms and significance
}

\author{
Corrine Lenahan and David Avigan
}

Division of Hematology/Oncology, Beth Israel Deaconess Medical Center, 330 Brookline Avenue, Boston, MA 02215, USA

Corresponding author: David Avigan, davigan@bidmc.harvard.edu

Published: 5 January 2006

Breast Cancer Research 2006, 8:101 (doi:10.1186/bcr1375)

This article is online at http://breast-cancer-research.com/content/8/1/101

(c) 2006 BioMed Central Ltd

See related research by Pinzon-Charry et al. in this issue [http://breast-cancer-research.com/content/8/1/R5]

\begin{abstract}
Dendritic cells (DCs) are a complex network of antigenpresenting cells that have an essential role in the modulation of primary immunity. There has been increasing evidence that DCs isolated from patients with malignancy demonstrate functional deficiencies that inhibit the capacity to mount an effective antitumor response. In this issue of Breast Cancer Research, PinzonCharry and colleagues investigate one of the possible mechanisms by which tumors induce DC dysfunction to evade host immune surveillance. They demonstrate that DCs isolated from the circulation of patients with early-stage breast cancer exhibit increased rates of spontaneous apoptosis. In vitro studies suggest that a soluble factor secreted by breast cancer cells is responsible for this phenomenon. In contrast, ex vivo conditioning of DCs with CD-40 ligand and IL-12 was protective against tumor-induced apoptosis.
\end{abstract}

Dendritic cells (DCs) are the most potent antigen-presenting cells and are uniquely capable of stimulating primary immune responses by the presentation of antigen in the context of high levels of costimulatory molecule expression [1,2]. The functional characteristics of DCs evolve with their stage of maturation. Immature DCs are found at sites of antigen capture and excel at antigen processing, but lack significant stimulatory capacity. After antigen uptake, DCs undergo further differentiation characterized by the loss of phagocytic capacity and increased expression of costimulatory molecules necessary for $\mathrm{T}$ cell activation. DC-based tumor vaccines are being explored as tumor immunotherapy. One approach involves the introduction of tumor-associated antigens or genes that are subsequently taken up by native DCs, which then migrate to the draining lymph node. An alternative strategy involves the administration of DCs manipulated ex vivo to express tumor antigens [3-7].
DCs isolated from cancer patients exhibit quantitative and functional deficiencies [8-11]. Decreased numbers of mature DCs have been demonstrated in the tumor bed, draining lymph nodes, and circulation in multiple tumor models. In patients with head and neck squamous cell carcinoma (HNSCC), numbers of DCs were halved in early-stage patients, with a further decrease in patients with more advanced disease [10]. DC subset analysis in patients with breast cancer and HNSCC has revealed that decreases in cell numbers are confined to DCs of the myeloid in comparison with those of the plasmacytoid or lymphoid lineage. Surgical debulking of breast and prostate cancer results in a corresponding increase in myeloid-derived DCs $[10,12]$. Minimal DCs are recruited to the tumor bed in patients with renal and prostate cancer. Those present have low levels of costimulatory molecules and a decreased capacity to stimulate allogeneic $T$ cell proliferation $[11,13]$. Similarly, DCs isolated from patients with colon cancer lack expression of CD80 or CD86. In vitro culture with granulocyte/macrophage colony-stimulating factor (GM-CSF) and CD40 ligand (CD40L) or tumor necrosis factor (TNF) did not result in the upregulation of costimulatory molecule expression, suggesting that tumor cells cripple the capacity of DCs to undergo normal differentiation [14]. In concert with these findings is the relative predominance of immature DCs in cancer patients that potentially induced tolerance by presenting tumor antigens in the absence of costimulatory signals.

In their study, Pinzon-Charry et al. [15] demonstrate that circulating DCs isolated from early-stage breast cancer have higher rates of spontaneous apoptosis than those from healthy controls. Whereas previous studies have demon-

$\mathrm{CD} 40 \mathrm{~L}=\mathrm{CD} 40$ ligand; $\mathrm{DC}=$ dendritic cell; GM-CSF = granulocyte/macrophage colony-stimulating factor; HNSCC $=$ head and neck squamous cell carcinoma; IL = interleukin; PBMC = peripheral blood mononuclear cell; TNF = tumor necrosis factor. 
strated that tumor cells induce apoptosis of blood DCs in vitro, this report suggests that the reduction in circulating DC populations arises from their increased rate of clearance in vivo. The authors argue that this phenomenon results in a lack of effective antigen presentation and contributes to a permissive environment for tumor growth. They demonstrate that a soluble factor contained in supernatant derived from cultured breast cancer cell lines induces DC apoptosis. Pinzon-Charry et al. show that 24-hour culture with tumorderived supernatant caused an increase in $\mathrm{Lin}^{-} \mathrm{HLA}^{-\mathrm{DR}^{+}}$ apoptotic cells as in comparison with DCs cultured with peripheral blood mononuclear cell (PBMC)-derived supernatant, supporting the authors' hypothesis that tumor products were responsible for the elevated proportions of apoptotic blood DCs in the patients with breast cancer. A variety of tumor-derived factors have been identified that disrupt DC maturation and function, including IL-10 and vascular endothelial growth factor [16,17]. IL-10, for example, irreversibly blocks DC differentiation and induces CD4 and $\mathrm{CD}^{+} \mathrm{T}$ cells that suppress antigen-specific responses [17].

It has been shown that IL-12 enhances the function of DCs and promotes the differentiation and maturation of DCs indirectly by the production of proinflammatory cytokines such as interferon- $\gamma$, TNF- $\alpha$, IL- 6 and GM-CSF [18]. DCs express IL-12 receptors, and their occupation initiates the nuclear localization of members of the NF- $\mathrm{KB}$ family of transcription factors [19]. IL-12 has also been reported to be an anti-apoptotic factor for DCs, and a lack of production of IL-12 by DCs may lead to early cell death. Pinzon-Charry et al. demonstrate that incubation of DCs with CD4OL was protective against tumor-associated apoptosis. CD40 ligation induced a modest increase in TNF- $\alpha$ and more marked increases in IL-12 production. Culture with IL-12 alone also reversed the pro-apoptotic effects of tumor supernatant. It is noteworthy that exposure to tumor supernatant resulted in a downregulation of $\mathrm{Bcl}-2$ expression, which was reversed by preincubation with IL-12 or CD40L. IL-12 has been reported to protect in vitro derived DCs from apoptosis in prostate cancer [20]. In contrast, IL-12 did not prevent tumorassociated apoptosis when added to PBMCs during early DC development.

\section{Significance for immunotherapy}

The findings presented by Pinzon-Charry et al. [15] help to further define the immunologic milieu that fosters tumor immune tolerance and carry important implications for the design of immunotherapeutic strategies. The increased susceptibility of blood DCs to apoptosis may result in a diminished capacity to respond to tumor vaccines that depend on in vivo antigen loading of native DCs. One strategy to circumvent this limitation is through the use of DCs generated ex vivo that are loaded with tumor antigens. Another strategy involves the administration of adjuvant cytokines such as IL-12 to reverse the tumor-associated inhibition of DCs. IL-12 has been shown to augment the efficacy of cancer vaccines. IL-12 enhances the response to vaccination with DC/tumor fusions in animal models and clinical studies [21].

\section{Competing interests}

The author(s) declare that they have no competing interests.

\section{References}

1. Avigan D: Dendritic cells: development, function and potential use for cancer immunotherapy. Blood Rev 1999, 13:51-64.

2. Banchereau J, Steinman RM: Dendritic cells and the control of immunity. Nature 1998, 392:245-252.

3. Knutson KL, Schiffman K, Cheever MA, Disis ML: Immunization of cancer patients with a HER-2/neu, HLA-A2 peptide results in short-lived peptide-specific immunity. Clin Cancer Res 2002, 8:1014-1018.

4. Boczkowski D, Nair SK, Snyder D, Gilboa E: Dendritic cells pulsed with RNA are potent antigen-presenting cells in vitro and in vivo. J Exp Med 1996, 184:465-472.

5. Hsu FJ, Benike C, Fagnoni F, Liles TM, Czerwinski D, Taidi B, Engleman EG, Levy R: Vaccination of patients with B-cell lymphoma using autologous antigen-pulsed dendritic cells. Nat Med 1996, 2:52-58.

6. Banchereau J, Palucka AK, Dhodapkar M, Burkeholder S, Taquet N, Rolland A, Taquet S, Coquery S, Wittkowski KM, Bhardwaj N, et al:: Immune and clinical responses in patients with metastatic melanoma to CD34+ progenitor-derived dendritic cell vaccine. Cancer Res 2001, 61:6451-6458.

7. Nestle FO, Alijagic S, Gilliet M, Sun Y, Grabbe S, Dummer R, Burg G, Schadendorf D: Vaccination of melanoma patients with peptide- or tumor lysate-pulsed dendritic cells. Nat Med 1998, 4:328-332.

8. Brown RD, Pope B, Murray A, Esdale W, Sze DM, Gibson J, Ho PJ, Hart D, Joshua D: Dendritic cells from patients with myeloma are numerically normal but functionally defective as they fail to up-regulate CD80 (B7-1) expression after huCD40LT stimulation because of inhibition by transforming growth factor-beta1 and interleukin-10. Blood 2001, 98:29922998.

9. Gabrilovich DI, Ciernik IF, Carbone D: Dendritic cells in antitumor immune responses. I. Defective antigen presentation in tumor-bearing hosts. Cell Immunol 1996, 170:101-110.

10. Hoffman TK, Muller-Berghaus J, Ferris RJ, Johnson JT, Storkus WJ, Whiteside TL: Alterations in the frequency of dendritic cell subsets in the peripheral circulation of patients with squamous cell carcinomas of the head and neck. Clin Cancer Res 2002, 8:1787-1793

11. Troy AJ, Summers KL, Davidson PJ, Atkinson CH, Hart DN: Minimal recruitment and activation of dendritic cells withing renal cell carcinoma. Clin Cancer Res 1998, 4:585-593.

12. Della Bella $S$, Gennaro M, Vaccari M, Ferraris $C$, Nicola S, Riva A, Clerici M, Greco M, Villa ML: Altered maturation of peripheral blood dendritic cells in patients with breast cancer. $\mathrm{Br} J$ Cancer 2003, 89:1463-1472.

13. Troy A, Davidson P, Atkinson C, Hart D: Phenotypic characteristics of dendritic cell infiltrate in prostate cancer. J Urol 1998, 160:214-219.

14. Chaux P, Favre N, Martin M, Martin F: Tumor-infiltrating dendritic cells are defective in their antigen presenting function and inducible B7 expression in rats. Int J Cancer 1997, 72: 619-624.

15. Pinzon-Charry A, Maxwell T, McGuckin MA, Schmidt C, Furnival C, Lopez JA: Spontaneous apoptosis of blood dendritic cells in patients with breast cancer. Breast Cancer Res 2006, 8:R5.

16. Gabrilovich DI, Chen HL, Girgis KR, Cunningham HT, Meny GM, Nadaf S, Kavanaugh D, Carbone DP: Production of vascular endothelial growth factor by human tumors inhibits the functional maturation of dendritic cells. Nat Med 1996, 2:10961103.

17. Steinbrink K, Graulich E, Kubsch S, Knop J, Enk A: CD4+ and CD8+ anergic $T$ cells induced by interleukin-10-treated human dendritic cells display antigen specific suppressor activity. Blood 2002, 99:2468-2476.

18. Portielje JE, Gratama JW, van Ojik HH, Stoter G, Kruit WH: IL-12: a promising adjuvant for cancer vaccination. Cancer Immunol Immunother 2003, 53:133-144. 
20. Pirtskhalaishvili G, Shurin GV, Eshe C, Cai Q, Salup RR, Bykovskaia SN, Lotze MT, Shurin MR: Cytokine-mediated protection of human dendritic cells from prostate cancer-induced apoptosis is regulated by the $\mathrm{Bcl}-2$ family of proteins. $\mathrm{Br} J$ Cancer 2000, 83:506-513.

21. Kikuchi T, Akasaki Y, Abe T, Fukuda T, Saotome H, Ryan JL, Kufe DW, Ohno T: Vaccination of glioma patients with fusions of dendritic and glioma cells and recombinant interleukin 12. J Immunother 2004, 27:452-459. 